\title{
Landslide Detection Based on Bayesian Classification Method
}

\author{
Pushparaj. D, Uma priyadarsini
}

\begin{abstract}
The study of landslide is a very difficult task due to high space temporal variety of involved parameters. The study of munnar city landslide has been performed by a data mining method called Bayesian classification. The dataset related to detect the landslide were soil and moisture parameters. These data sets are the basis of this work. The cumulative pattern related to the landslides depends on the data accumulated from the various sensors like geophysical sensor and moisture, soil sensor.
\end{abstract}

Keywords: landslide, Bayesian classification, rainfall rate, geographical sensor, moisture sensor.

\section{INTRODUCTION}

In india landslides occurs due to heavy rainfall. The landslides causes a loss of ifes, damage to the communication routes and some time they cause damage to the agriculture by damaging the fields. Munnar, the southeast space of Kerala expertise several forms of landslides, of that rubble flows are the most common. Studies conducted within the space indicates that prolonged and intense rain or a lot of significantly a combination of the 2 and therefore the resultant pore pressure variations are the foremost vital trigger of landslides therein space. Appropriate applied mathematics techniques are used for analyzing the interdependability of those factors and thereby effectively crucial the pattern for pore pressure buildup.

The remainder of the paper is organized as follows. Section II describes connected potential zone idendification. Section III explains the automatic information analysis. Section VI pander to the experimentation and analysis of the projected algorithms.

\section{2. RELATED WORKS:}

Kumar Rai in 2012. Avalanche is a type of slant process which focuses to the transmission and descending development of materials, for example, soil and shake mass. Reliably torrential slide assumes a mind-boggling death toll and damage to property. It in like manner ends up hard to give minute lightening measure.For the present examination, Narmab bowl has been chosen which is arranged in the southern piece of Minūdasht Township in Golestan region of Iran. The most influenced towns are Nishak, Saran and Takht. The masses living in these towns encounter the evil impacts of the flood of torrential slide. In like manner, torrential slide weakness mapping is one of the fundamental issues for urban and provincial orchestrating in Iran. In this examination, layers are reviewed with the assistance of

Revised Manuscript Received on July 10, 2019.

Pushparaj. D, UG Scholar AssistantProfessor , Saveetha of engineering, Tamil Nadu, pushparajd17@gmail.com,

Uma priyadarsini, Department Of Computer Science and Engineering, Saveetha of engineering, Tamil Nadu, India (Email: umaps2014@gmail.com) vigor considers used to pass on heavy slide slightness plot Multiple Linear Regression methodology. The parameters of incline, point of view, lithology, arrive cover, precipitation and division from blame, remove from stream, and segment from street were utilized as factors in the Multiple Linear Regression examination. Ilwis 3.3 Academic, Arc GIS 9.3, Global Mapper 13.0 and Excel programming ventures have been used for zonation, and quantifiable examinations exclusively. At last, an overlay examination is done by reviewing the layers got by their perceived coefficient in persuading model.The outcome was confirmed utilizing the Area under Curve(AUC) framework and regular information of exuberant slide events. The endorsement results showed classy ascension between the shortcoming outline the present data on torrential slide territories. In this manner, the accomplishment rate of the model (79.7\%) demonstrates elevated standard precision.

Richard M. Iverson in 2000. Land sliding in light of precipitation includes physical procedures that work on divergent timescales. Connections between these timescales manage advancement of a numerical model that utilizes diminished types of Richards' condition to assess impacts of precipitation penetration on avalanche event, timing, profundity, and quickening in assorted circumstances. The longest relevant timescale is $\mathrm{A} / \mathrm{D} 0$, where $\mathrm{D} 0$ is the most extreme water driven diffusivity of the dirt and An is the catchment zone that possibly influences groundwater weights at an imminent avalanche slip surface area with areal directions $\mathrm{x}, \mathrm{y}$ and profundity $\mathrm{H}$. Times more prominent than A/D0 are fundamental for foundation of relentless foundation water weights that create at $(x, y, H)$ in light of precipitation arrived at the midpoint of over periods that usually run from days to numerous decades. These consistent groundwater weights impact the inclination for landsliding at $(\mathrm{x}, \mathrm{y}, \mathrm{H})$, yet they don't trigger slant disappointment. Disappointment results from precipitation over a normally shorter timescale H2/D0 related with transient pore weight transmission amid and following tempests. Normally, this timescale ranges from minutes to months. The most limited timescale affecting exuberant slide reactions to precipitation is $=\mathrm{H} / \mathrm{g}$, where $\mathrm{g}$ is the proportion of gravitational quickening. Post disappointment avalanche movement happens on this timescale, which demonstrates that the most slender avalanches quicken most rapidly if every single other factor are steady. Impacts of hydrologic forms on avalanche forms over these various timescales are embodied by a reaction work, $\mathrm{R}(\mathrm{t} *) 5=\mathrm{t} * / \mathrm{p}$ $\exp \left(21 / t^{*}\right) 2 \operatorname{erfc}\left(1 /=t^{*}\right)$, which depends just on 
standardized time, $\mathrm{t}^{*}$. Utilization of $\mathrm{R}\left(\mathrm{t}^{*}\right)$ related to topographic information, precipitation force and length data, an unbounded incline disappointment model, and Newton's second law predicts the planning,profundity, and speeding up of precipitation activated avalanches. Information from differentiating avalanches that show fast, shallow movement and moderate, profound situated movement certify these forecasts.

Chowdhury \& Phil Flentje in 2002. The paper tends to the fundamental vulnerabilities related withh the event of precipitation initiated avalanches. Spatial changeability of site conditions, nearby geography and precipitation contributes altogether to the vulnerability of utilizes novel information accumulation strategies for power improvement in the field arrangement. A give an account of unexpected difficulties that were looked in the field organization of the remote sensor systems and the novel arrangements concocted to conquer them are exhibit 4. Tony L. T. Zhan and Charles W. W. Ng, M.ASCE in 2004. To enhance the comprehension of the impact of water driven properties and precipitation conditions on precipitation invasion instrument and thus on the pore avalanche peril. Urban avalanche issues require the administration of slants of peripheral steadiness. Appraisal of danger, weakness and hazard require the utilization of observational methodologies, the examination of precipitation information and the connection between precipitation sizes from one viewpoint and incline development on the other. Nuances of research did in the Illawarra zone of New South Wales, Australia are given. Reference is made to the broad database enabling the affirmation of torrential slide frequencies. The idea of precursor precipitation rate exceedance time (ARPET) is clarified. The utilization of construed edge precipitation sizes for ongoing expectation and cautioning is clarified. Vulnerabilities worried about this methodology are investigated with specific reference to precipitation conveyances in the examination territory.

Maneesha Vinodini Ramesh in 2014. Remote sensor frameworks are a champion among the most reassuring creating headways, allowing to consistency checking of topographical territories (remote and undermining) that are slanted to disasters. With a thought on exuberant slide affirmation, this work reaffirms the limit of remote sensor systems for disaster alleviation. An absolute down to earth system containing 50 land sensors and 20 remote sensor centers was passed on in Idukki, a locale in the southwestern area of Kerala State, India, a very torrential slide slanted district. The remote sensor arrange structure has, for up to three years, amassed gigantic proportions of data, for instance, associated sensor data regards on precipitation, sogginess, pore weight and improvement, close by other topographical, hydrological and soil properties, giving a prevalent appreciation of the torrential slide circumstance. Utilizing the remote sensor systems, framework was produced an inventive three dimension avalanche cautioning framework (Early, Intermediate and Imminent). This framework has demonstrated its legitimacy by conveying a genuine cautioning to the nearby network amid substantial rains in the July 2010 rainstorm season. The execution of this framewor. water weight conveyances in single and unsaturated soil frameworks, a logical parametric investigation has been done. Parameters considered in this investigation incorporate immersed porousness sksd, desaturation coefficient (a), water stockpiling limit sus-urd, and predecessor and ensuing precipitation invasion rate $(\mathrm{qA}$ and $\mathrm{qB}$ ). In addition, the impact of soil profile heterogeneity is additionally explored. The determined outcomes show that the penetration procedure and pore-water weight reaction are essentially constrained by both $\mathrm{qa} / \mathrm{ks}$ and $\mathrm{ks} / \mathrm{a}$. For the most part the bigger the estimation of $\mathrm{qa} / \mathrm{ks}$, the more prominent the decrease of negative pore-water weight in shallow soil layer. The bigger the proportion of ks/a, the quicker is the headway of wetting front. Among the three water powered parameters, the impacts of an and ks on porewater weight reaction are substantially more noteworthy than that of sus-urd. Be that as it may, the general significance of ks and a relies upon the underlying negative pore-water weight territory in the ground. What's more, the impact of forerunner invasion rate sqAd on pore-water weight reaction seems, by all accounts, to be considerably more huge than that of ensuring penetration rate sqBd.

\section{EXPERIMENTATION AND RESULTS:}

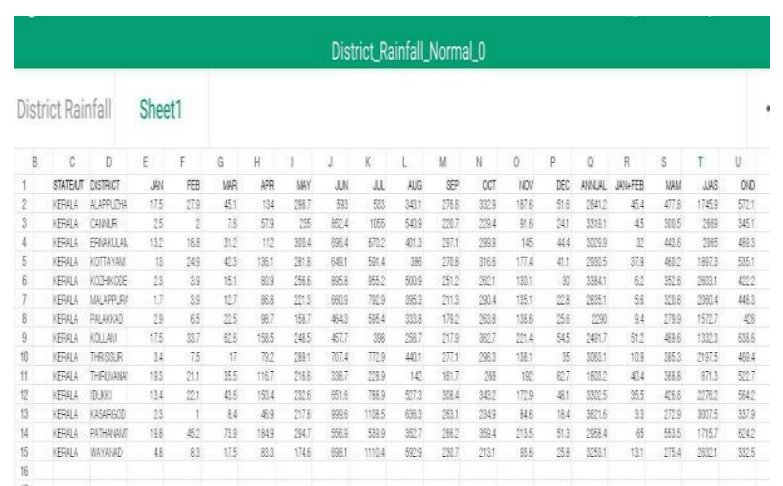

Fig 1. Rainfall dataset of Kerala 2018.

The fundamental quantity information from this technique is ceaselessly collected from 2008 ahead. As of March 2019, the system has ceaselessly collected around one hundred Million observations, with sixty choices along with measuring instrument readings, downfall reading etc from 100 and fifty earth science sensors. the entire information from the dataset is analyzed victimization fully completely different situations thus on see the correlations between them. As mentioned earlier, this study is very centered on 2 factors viz. rain rate and pore pressure values. Those knowledge are capable to capture the initial triggers and indications of slope instability. so throughout this work, gage and pore pressure device information along with soil properties are used for developing the primary warnings. thus the entire kind of feature is reduced to around thirty numbers that forms the initial step of spatial property reduction of the dataset. These observations from the reduced feature set are then mass victimization acceptable math ways explained on top of for any spatial property reduction and so reduced to around one 10000 observations. Using rule one, the rain rate of 2010 and 2011 are analyzed thus on spot the pattern and intensity of downfall at fully

Published By: 
completely different times throughout a year viz. 'no rain' season and 'rainy' season so as that it's used for analyzing the results of the antecedent rain conditions on the pore pressure price. the data analysis was principally performed by that specialize in the info from these rainy periods and conjointly the correlations are analyzed supported the fundamental quantity of the 'rainy' and 'no rainy' days and additionally the intensity of rain throughout the 'continuous rainy'days.

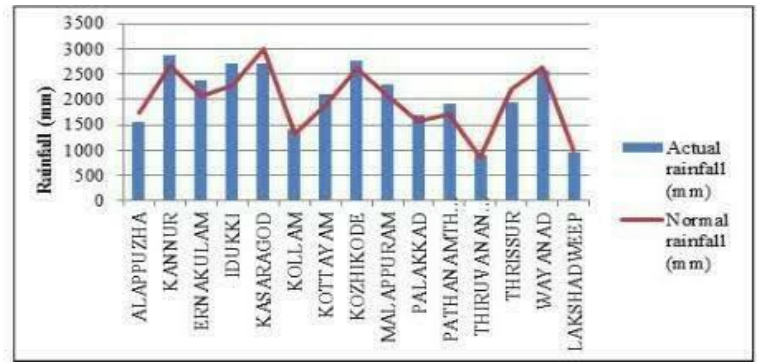

Fig 2. The rainfall report in Kerala 2018.

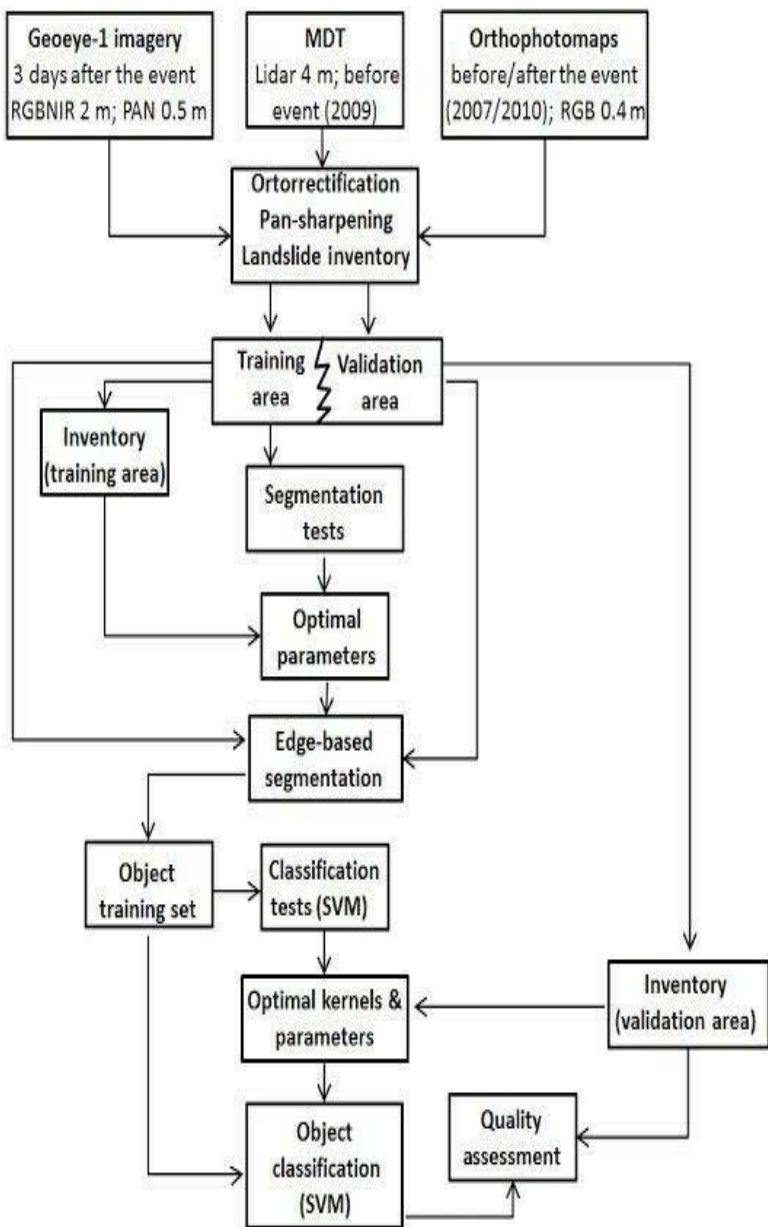

Fig 3. Bayesian classification of safe location

Data received at the DMC is being been analyzed using the integrated landslide modeling software and the in- house designed data visualization software, which has the capability to determine factor of safety of the mountain and probability of landslide occurrence with respect to the signals received from the deployed sensors. It also has the capability to compare and analyze data from different sensor columns, different sensors, selective comparison, etc. Data is successfully received from the deployment site with minimal data packet loss and analysis of data has been performed. Data received from two pore pressure transducers and a rain gauge is shown in Figure 1. During 2010 monsoon season, the sensors were able to capture the expansion and contraction of soil mass during and after heavy rainfall.

The data analysis software showed respective in each of the deployed sensors. The data analysis software has been integrated with the capability of real streaming of data over internet. The scientists around the world can analyze the data with very minimal delay and effective warning can be issued on time.

\section{CONCLUSION AND FUTURE WORK:}

Real time observation of landslides is one of the difficult analysis areas accessible nowadays inside the sector of geology analysis. This paper discusses the event of associate degree actual field activity of a wireless detector network primarily based landslide detection system. this technique uses a heterogeneous network composed of wireless detector nodes, Wi-Fi, and satellite terminals for economical delivery of real time data to the data management center, to enable sophisticated analysis of the data and to provide landslide warnings and risk assessments to the inhabitants of the region. A check setup of this vogue has been already deployed at Anthoniyar Colony, Munnar, Idukki, Kerala, India. within the future, this work are extended to a full reading by exploitation the teachings learned from the prevailing network. This network are used for understanding the power and value of wireless detector network for vital and emergency application.

\section{REFERENCE:}

1. P. Samuia, D.P. Kothari, "Utilization of a least square support vector machine (LSSVM) for slope stability analysis", ScientiaIranica, Transactions A: Civil Engineering 18, 5358, 2011.

2. Mohammad Onagh, V.K. Kumar and Praveen Kumar Rai, Application of multiple linear regression model in landslide susceptibility zonation mapping, International Journal of Geology, Earth and Environmental Sciences, Vol. 2 (2), pp.87-101 May-August 2012.

3. Tony L. T. Zhan1 and Charles W. W. Ng, "Analytical Analysis of Rainfall Infiltration Mechanism in Unsaturated Soils", International Journal of Geomechanics (C) ASCE, December 2004.

4. Ramesh. M.V, Ushakumari. P, "Threshold Based Data Aggregation Algorithm To Detect Rainfall Induced Landslides", in Proceedings of the 2008 International Conference on Wireless Networks (ICWN'08), Vol. 1,Pages 255-261, CSREA Press, July, 2008.

5. Maneesha V. Ramesh, Nirmala Vasudevan "The deployment of deep earth sensor probes for landslide detection" Landslides, Pages 457-474, December 2011.

6. LAN Hengxing, ZHOU Chenghu, C. F. Lee,WANG Sijing WU Faquan "Rainfall-induced landslide stability analysis in response to transient pore pressure "Science in China Ser.E.Technological Sciences vol.46 supposed. 52_68, 2003. 